\title{
PROCESY FILTRACYJNE WSPOMAGANE MICELAMI - PRZEGLĄD STOSOWANYCH SURFAKTANTÓW
}

\section{MICELLE ENHANCED FILTRATION PROCESSES \\ - A SHORT INSIGHT INTO USED SURFACTANTS}

\author{
Marek Bryjak \\ Wydziat Chemiczny, Politechnika Wrocławska, \\ Wyb. Wyspiańskiego 27, \\ 50-370 Wroctaw \\ e-mail:Marek.bryjak@pwr.edu.pl
}

\author{
Abstract \\ Wprowadzenie \\ 1. Filtracja wspomagana micelami \\ 1.1. Usuwanie kationów \\ 1.2. Usuwanie anionów \\ 1.2. Usuwanie substancji niejonowych \\ Uwagi końcowe \\ Piśmiennictwo cytowane
}




\begin{abstract}
The short review describes typical surfactants used for micelle enhanced ultrafiltration (MEUF). Concerning the kind of pollutant that has to be removed from aqueous solutions, different surface-active species can be applied. However, to get the efficient separation two bodies have to be selected: a specific surfactant and an ultrafiltration membrane. Each procedure has its own rules to be fulfilled.
\end{abstract}

Keywords: water treatment, filtration, surfactants

Słowa kluczowe: uzdatnianie wody, filtracja, surfaktanty 


\section{WPROWADZENIE}

Obserwowane ostatnio zmiany klimatyczne zmuszają do radykalnej zmiany sposobu korzystania $\mathrm{z}$ wody. $\mathrm{Z}$ jednej strony sięga się do wody morskiej czy zasolonych wód podziemnych, a $\mathrm{z}$ drugiej coraz częściej odzyskuje się wodę ze ścieków przemysłowych czy miejskich. Racjonalna gospodarka wodą została wpisana do dwóch kluczowych dokumentów: rezolucji Organizacji Narodów Zjednoczonych wdrażającej Cele Zrównoważonego Rozwoju oraz do działań Unii Europejskiej wyznaczonych w Zielonym Ładzie.

Sprostanie wymaganiom jakości wody możliwe jest przy zastosowaniu niskoenergetycznych technik separacyjnych. $Z$ dobrym powodzeniem te wymagania spełniają metody membranowe, a ich popularność wynika z następujących powodów: i) są one wysoce selektywne, ii) wymagają niskich nakładów energetycznych, iii) ich modułowość umożliwia integrowanie z istniejącymi ciągami technologicznymi, iv) są łatwo skalowalne, v) są elastyczne, oraz v) są praktycznie bezobsługowe. W przypadku procesów ciśnieniowych, w zależności od wielkości separowanych cząsteczek/cząstek, wyróżnia się mikrofiltrację (MF cząstki mniejsze niż $0,1 \mu \mathrm{m}$ ), ultrafiltrację (UF w zakresie 10 $\mathrm{nm}-0,1 \mu \mathrm{m}$ ), nanofiltrację (NF w zakresie $1 \mathrm{~nm}-10 \mathrm{~nm}$ ) i odwróconą osmozę (RO cząsteczki mniej niż $1 \mathrm{~nm}$ ). Procesy prowadzi się pod następującymi ciśnieniami: MF do 0,1 MPa, UF do 0,5 MPa, NF do $1 \mathrm{MPa}$ i RO do $5 \mathrm{MPa}$ a ich koszty, wywołane głównie kosztami wytwarzania ciśnienia, zmieniają się $\mathrm{w}$ szeregu $\mathrm{MF}<\mathrm{UF}<\mathrm{NF}<\mathrm{RO}$. W związku $\mathrm{z}$ tym pojawia się problem, jak wydzielać substancje o małych wymiarach nie stosując wysokich ciśnień? Jednym z rozwiązań jest wykorzystanie procesów hybrydowych, w których cząsteczki o małych wymiarach wiążą się z dużymi obiektami (substancjami wiążącymi) i jako kompleksy są wydzielane w procesie mikro- lub ultrafiltracji. Zatężone kompleksy poddawane są regeneracji, a substancje wiążące ponownie zawracane do sorpcji. Jako substancje wiążące stosowane są: polimery rozpuszczalnie w wodzie, micele surfaktantów lub drobnoziarniste sorbenty stałe (wymieniacze jonowe, żywice chelatujące, polimery z odciskami molekularnymi). Pełne omówienie stosowanych substancji wiążących znaleźć można w literaturze [1].

\section{FILTRACJA WSPOMAGANA MICELAMI}

Proces ten, opisany przez Scamehorn w latach 80 [2], bazuje na fakcie, że jony lub małe cząsteczki substancji organicznej wiążą się z powstałymi micelami i jako większe obiekty zostają zatrzymane przez membrany ultrafiltracyjne. W wiązaniu uczestniczą odziaływania: jonowe, gdy mamy do czynienia $\mathrm{z}$ surfaktantami jonowymi czy hydrofobowe, gdy w grę wchodzą surfaktanty niejonowe. We wszys- 
tkich przypadkach stężenie surfaktantu w roztworze wodnym musi być większe od krytycznego stężenia micelarnego (CMC).

Mimo tego, że znane jest wiele typów związków powierzchniowoczynnych, w procesach filtracyjnych wspomaganych micelami wykorzystuje się zwykle sól sodową kwasu dodecylosiarkowego (SDS), eter glikolupolietylenowego z p-tertoktylofenolem (TX-100) lub bromek heksadecylotrimetyloamoniowy (CTAB). Wynika to $\mathrm{z}$ dostępności tych surfaktantów. Ich właściwości zostały dobrze poznane (w tym wartości CMC) oraz są dane o ich wykorzystaniu w procesach hybrydowych. Wielkości CMC dla podanych trzech typów surfaktantów wynoszą odpowiednio: SDS - 8,3 mM, TX-100 -0,25 mM, CTAB- 0,9 mM [4]. Należy podkreślić, że o efektywności filtracji wspomaganej micelami decydują nie tylko cechy samego surfaktantu (zdolność do tworzenia micel, czy właściwości hydrofilowo-hydrofobowe) ale również cechy stosowanych membran w tym ich porowatość, dystrybucja wielkości porów, hydrofobowość/hydrofilowość powierzchni czy gładkość [4]. W trakcie procesu filtracji na powierzchni membran osadzają się filtrowane substancje powodując blokowanie porów a w konsekwencji zmniejszenie strumienia permeatu. W takim przypadku proces filtracji jest przerywany a membrana poddawana regeneracji. Im dłuższy jest jej czas między kolejnymi cyklami regeneracji, tym proces jest bardziej ekonomiczny. Zatem w projektowaniu procesu wspomaganego micelami należy umiejętnie dobierać nie tylko surfaktanty, ale również i membrany.

\subsection{USUWANIE KATIONÓW}

Dobór surfaktantu zależny jest od rodzaju substancji, którą należy usunąć z roztworu wodnego. W przypadku usuwania kationów, gdy stosowany jest SDS osiągnięcie CMC wymaga dużych stężeń surfaktantu, a w permeacie (filtracie) pojawiają się jego cząsteczki. Otrzymana woda nie jest wodą spełniającą normy wody pitnej, ma za dużą zawartość węgla organicznego i wysoką wartość chemicznego zapotrzebowania na tlen. W przeciwieństwie do jonowych surfaktantow, zastosowanie niejonowych analogów nie powoduje tak drastycznego zanieczyszczenia wody. Niestety surfaktanty niejonowe są nieefektywnie w usuwania kationów. W celu zmniejszenia efektu przenoszenia jonowych surfaktantów z fazy zasilającej do permeatu (filtratu) stosowane są zwykle dwie procedury: tworzenie micel z mieszanin surfaktantu jonowego $\mathrm{z}$ niejonowym $\{5,6]$ lub też stosowania ligandów [7,8]. Czasami jako ligand wykorzystywany jest polimer, który nie tylko wzmacnia strukturę micel, ale również uczestniczy $\mathrm{w}$ procesie wiązania zanieczyszczeń [9-11]. W tabeli poniżej podano kilka przykładów ilustrujących wydzielanie kationów metali ciężkich z roztworów wodnych. 
Tabela 1. Usuwanie kationów metali ciężkich z wykorzystaniem filtracji wspomaganej micelami

Table 1. Removal of heavy metals by micelle enhanced ultrafiltration

\begin{tabular}{|l|l|l|}
\hline Usuwane kationy & Surfaktant & Lit \\
\hline $\mathrm{Ni}$ & SDS & 12 \\
\hline $\mathrm{Cd}$ & SDS & 13 \\
\hline $\mathrm{Cd}$ & Ramnolipid biosurfaktant & 14 \\
\hline $\mathrm{Cd}$ & SDS & 15 \\
\hline $\mathrm{Zn}, \mathrm{Mn}, \mathrm{Ni}$ & SDS & 16 \\
\hline $\mathrm{Pb}, \mathrm{Cd}, \mathrm{Zn}$ & SDS & 17 \\
\hline $\mathrm{Pb}$ & SDS & 18 \\
\hline
\end{tabular}

\subsection{USUWANIE ANIONÓW}

Usuwanie anionów stanowi już mniejszy problem. Dostępne surfaktanty, np. CTAB, ODA, OTAB czy CPC, tworzą micele przy mniejszych stężeniach i do permeatu przenika mniej związków powierzchniowoczynnych. Jednak i w tym przypadku wykorzystuje się micele mieszane [19]. W tabeli 2 zebrano kilka przykładów ilustrujących omawiane zagadnienie

Tabela 2. Usuwania anionów $\mathrm{z}$ wykorzystaniem filtracji wspomaganej micelami Table 2. Removal of anions by micelle enhanced ultrafiltration

\begin{tabular}{|l|l|l|}
\hline Usuwane aniony & Surfaktant & Lit \\
\hline $\mathrm{AsO}_{4}$ & DPC & 20 \\
\hline $\mathrm{AsO}_{4}$ & CPC & 21 \\
\hline $\mathrm{SO}_{4}$ & CTAB & 22 \\
\hline $\mathrm{BO}_{4}$ & CPC & 23 \\
\hline $\mathrm{NO}_{3}, \mathrm{Cl}, \mathrm{HCO}_{3}, \mathrm{AsO}_{4}$ & CPC & 24 \\
\hline $\mathrm{NO}_{3}, \mathrm{AsO}_{4}$ & CPC & 25 \\
\hline $\mathrm{AsO}_{4}$ & CPC & 26 \\
\hline
\end{tabular}

\subsection{USUWANIE SUBSTANCJI NIEJONOWYCH}

Filtracja wspomagana micelami stosowana jest również do usuwania $\mathrm{z}$ wody substancji niejonowych. W tym przypadku micele tworzone są głównie przez niejonowe surfaktanty. Nie należy jednak myśleć, iż jedynie one są zdolne do solubilizacji wydzielanych $\mathrm{z}$ wody substancji. Zjawisko to zachodzi również w przypadku stosowania surfaktantów jonowych, czy też mieszanych. Dla ilustracji zagadnienia, w tabeli 3 podano kilka przykładów. 
Tabela 3. Usuwanie substancji niejonowych z wykorzystaniem filtracji wspomaganej micelami

Table 3. Removal of neutral species by micelle enhanced ultrafiltration

\begin{tabular}{|l|l|l|}
\hline Usuwane substancje & Surfaktant & Cyt \\
\hline$o$-toluidina & SDS & 27 \\
\hline Barwniki Red RB oraz Turquoise Blue & Ekstrakty z Sapindus rarak & 28 \\
\hline Barwnik methyl-orange (MO) & rodzina CTAB & 29 \\
\hline Fenol & Esterquat, DBSS, Lutensol AO 7 & 30 \\
\hline
\end{tabular}

Omawiając filtrację wspomaganą membranami nie można zapomnieć o samych membranach. Jak wspomniano odpowiedni dobór materiałów, z których są one wykonane, charakterystyka ich porowatości, gładkości powierzchni czy polidyspersyjność wymiaru porów ma istotny wpływ na sprawność procesu filtracji. Odporność na zmiany ciśnienia (tak istotna w przypadku stosowania mycia wstecznego membran) czy na agresywne odczynniki chemiczne (wykorzystywane w regeneracji chemicznej) stanowią dodatkowe elementy, które muszą być brane pod uwage przy doborze membran [30-34]. Zagadnienia te wychodzą jednak poza ramy niniejszego opracowania i nie są tu omawiane.

\section{UWAGI KOŃCOWE}

Proces filtracji wspomaganej micelami stanowi ciekawe rozwiązanie pozwalające w ekonomiczny sposób nie tylko usuwać z wody określone substancje, ale również pozyskiwać surowce z rozcieńczonych roztworów. Wymaga on doboru odpowiednich surfaktantów, stosowanych membran oraz warunków prowadzonej separacji. $\mathrm{W}$ przedstawionym materiale omówiono jedynie drobny fragment $\mathrm{z}$ ponad 300 publikacji (baza WoS), których wiodącym tematem była filtracja wspomagana micelami (MEUF).

\section{PIŚMIENNICTWO CYTOWANE}

[1] N. Kabay, M. Bryjak, Hybrid processes combining sorption and membrane filtration, w Encyclopedia of Membrane Science and Technology ed. E.M.V. Hoek, V.V. Tarabara, Wiley \& Sons 2013, 1341-1361.

[2] R.O. Dunn, J.F. Scamehorn, S.D. Christian, Colloids Surf., 1989, 35, 49.

[3] L.L. Gibbs, J.F. Scamehorn, S.D. Christian, J. Membr. Sci., 1987, 30, 67.

[4] M. Schwarze, Environ. Sci. Water Res. Technol., 2017, 3, 598.

[5] P. Yenphan, A. Chanachai, R. Jiraratananon, Desalination, 2010, 253, 30.

[6] C.-K. Liu, C.-W. Li, C.-Y. Lin, Chemosphere, 2004, 57, 629.

[7] B.R. Fillipi, J. F. Scamehorn, S.D. Christian, R.W. Taylor, J. Membr. Sci., 1998, 145, 27.

[8] C.-W.Li, C.-K.Liu, W.-S. Yen, Chemosphere, 2006, 63, 353.

[9] M. Bryjak, I. Duraj, G. Pozniak, Environ. Geochem. Health, 2010, 32, 275.

[10] L.C. Shen, A. Lo, X.T. Nguhen, N.P. Hankins, Sep. Purif. Technol., 2016, 159, 169.

[11] C. Ming, N.P. Hankins, J. Water Process. Eng., 34, 101170.

[12] W. Lin, L. Jing, B. Zhang, Water, 2020, 12, 1269. 
[13] J.H. Huang, S.H. Guo, G.M. Zeng, Y.L. Xiong, D.M. Zhang, X.J. Tang, G.X. Xie, Coll. Surf. A, 2012, 401, 81.

[14] S. Pal Verma, B. Sarkar, J. Water Process. Eng., 2020, 33, 101048.

[15] J. Huang, L. Shi, G. Zeng, H. Li, H. Huang, Y. Gu, Y. Shi, K. Yi, X. Li, J. Clean. Prod., 2019, 209, 53.

[16] V. Innocenzi, F. Tortora, M. Prisciandaro, I. De Michelis, F. Vegli, G. Mazziotti di Celso, J. Environ. Manage., 2018, 215, 377.

[17] X. Li, S. He, C. Feng, Y. Zhu, Y. Pang, J. Hou, K. Luo, X. Liao, Sustainability, 2018, 10, 92.

[18] D. Kumar Jana, K. Roy, S. Dey Sep. Purif. Technol., 2018, $207,28$.

[19] D. Şahin, S. Taşcıoğlu, Desalination Water Treat., 2018, 118,143.

[20] O.B. Gokcek, N. Uzal, Water Supply, 2020, 20, 574.

[21] M. Yaqub, S.H. Lee, Environ. Eng. Res., 2021, 26,190261.

[22] W. Lin, B. Zhang, X. Ye, K. Hawboldt, Environ. Sci. Pollut. Res., 2021, 28, 5609.

[23] F. Tortora, V. Innocenzi, G. Mazziotti di Celso, F. Vegliò, M. Capocelli, V. Piemonte, M. Prisciandaro, Desalination, 2018, 428, 21.

[24] M. Chen, K. Shafer-Peltier, S.J. Randtke, E. Peltier, Chemosphere, 2018, 213, 285.

[25] P. Bahmani, A. Maleki, R. Rezaee, M. Khamforoush, K. Yetilmezsoy, S.D. Athar, F. Gharibi, J. Water Process. Eng., 2019, 27, 24.

[26] P. Bahmani, A. Maleki, R. Rezaee, A.H. Mahvi, M. Khamforoush, S.D. Alhar, H. Daraei, F. Gharibi, G. McKay, J. Environ. Health Sci. Eng., 2019, 17, 115.

[27] P. Wu, Y. Liu, Y. Fu, S. Wang, H. Wang, J. Zhou, Environ. Technol., 2021, 42, 1506.

[28] N. Aryanti, A. Nafiunisa, T.D. Kusworo, D.H. Wardhani, Membranes, 2020, 10, 220.

[29] M. Schwarze, D. Seo, B. Bibouche, R. Schomäcker, J. Water Process. Eng., 2020, 36,101287.

[30] M.D. Víctor-Ortega, R.C. Martins, L.M. Gando-Ferreirab, R.M. Quinta-Ferreira, Coll. Surf. A, 2017, 531, 18.

[31] R. Field, Fundamental od fouling, w Membranes for Water Treatment, ed. K.V. Peinemann, S. Nune, Wiley \& Sons, 2010.

[32] G.K. Dhawan, Solutions to Membrane Fouling, https://www.watertreatmentguide.com/ membrane_fouling_solutions.htm.

[33] F. Beyer, J. Laurinonyte, A. Zwijnenburg, A.J.M. Stams, C.M. Plugge, J. Eng., 2017, ID 6356751.

[34] A. Drews, J. Memb. Sci., 2010, 363, 1.

Praca wpłynęła do Redakcji 18 maja 2021 r. 
